\title{
The analytic tradition in philosophy: volume $2-$ a new vision
}

\author{
Scott Soames 1
}

Published online: 20 March 2019

(c) Springer Nature B.V. 2019

This volume continues the story begun in volume 1, which focused on Frege, Moore, and Russell. Frege and Russell brought logic and philosophy of mathematics to center stage. Moore and Russell provided decisive criticisms of absolute idealism and pragmatism, while endorsing logico-linguistic analysis as a powerful tool for solving the problems of philosophy. Wittgenstein changed that in the Tractatus by substituting the study of logic, language, and meaning for attempts to solve traditional philosophical problems, which were seen as confusions to be avoided.

The atomist systems of Russell and Wittgenstein were driven by different visions. Russell's revisionary metaphysics was based on ideas of what reality must be like if it is to be knowable; Wittgenstein's system sought to explain what language and the world must be like, if the former was to represent the latter. Although the Tractatus opens with abstruse metaphysics, it doesn't tell us what the ultimate constituents of reality are, or how they are related. It neither identifies its metaphysical simples, nor analyzes statements of science or common sense.

The single great problem of the Tractatus, was, as Wittgenstein put it in the Notebooks, explaining the nature of propositions, which, for him, meant explaining meaning and finding the essence of representational thought and language. ${ }^{1} \mathrm{He}$ viewed his task as philosophical, because it involved finding the scope and limits of intelligibility. Assuming that to be intelligible a thought must provide information about which possible state the world is in, he concluded that informative thoughts are all contingent and knowable only aposteriori. Since he shared Russell's view that philosophical propositions are neither, he reasoned that there are none. Thus,

\footnotetext{
1 Wittgenstein (1914-16).

Scott Soames

soames@usc.edu

1 USC School of Philosophy, Mudd Hall of Philosophy, Los Angeles, USA
} 
his task was not to solve the problems of philosophy, but to dispose of them once and for all.

Chapter 2 of my volume explains, criticizes, and reconstructs an improved version of tractarian propositions that is consistent with many, though not all, tractarian doctrines. These include the picture theory of meaning, the theory of logical form, the truth-functionality of non-atomic propositions, and the rejection of Frege/Russell propositions in favor of a conception that ties propositions closely to representational uses of sentences or other artifacts.

Chapter 3 tackles the logic of the Tractatus, first providing essential but unstated detail needed to combine its unusual treatments of quantification and truthfunctionality. Next, I identify a problem about the totality of propositions that arises if there are infinitely many simple objects. I solve it in a tractarian friendly way using a reconstruction of tractarian propositions as acts of using sentences, and formulas, in accord with conventions governing them. This allows us to translate Tarski's trick of defining truth conditions of sentences from truth conditions of formulas relative to sequences into a tractarian trick of defining truth conditions of uses of sentences and formulas in accord with conventions. ${ }^{2}$ Chapter 3 also poses challenges for higher-order tractarian logic and for Wittgenstein's famous rejection of identity.

Chapter 4 illuminates the deeply flawed, but curiously beguiling, tractarian intelligibility test, and the lessons drawn from it about philosophy, value, the meaning of life. I close by rejecting a recent interpretation of Wittgenstein's ladder that portrays him as deliberately producing a compelling, but incoherent, work-not to reveal unstateable truths, but to demonstrate the impossibility of philosophy.

Part Two, on logical empiricism, begins in chapter 5 with the scientific positivism of Auguste Comte and Ernst Mach, who was the first Chair in Philosophy of Inductive Sciences at the University of Vienna. The discussion then moves, first, to the advances in logic, mathematics, and science made by Hilbert, Poincare, Duhem, and Einstein, next to the pivotal role of Moritz Schlick in leading the Vienna Circle, and finally to the mesmerizing impact of the Tractatus on its members. Schlick studied physics under Max Planck before becoming a philosopher of science and an epistemologist. In 1922, he took up Mach's old chair in Vienna. Having previously read Russell, he discovered the Tractatus, the anti-metaphysical tenor of which transformed his thought. This, in turn, led him to arrange extensive personal contact between Wittgenstein and members of the circle, prior to the 1929 publication of The Scientific Conception of the World. There the circle announced its existence, designating Einstein, Russell, and Wittgenstein as "leading representatives of the scientific world-conception."

Chapter 6 examines the attempt in Carnap's 1928 Aufbau to substitute the unity of science for metaphysics. Science, consisting of all objectively knowable truths, was to be unified by all-encompassing reductions based on logical analyses of scientific concepts. Since Carnap believed that unification could be achieved using different reductive bases, no single ontology was preferred to all others. Why did he

\footnotetext{
${ }^{2}$ Pp. 65-67.
} 
think this? Not surprisingly, verificationism was involved, as were other problematic doctrines. Still, his agenda was enlightening. The stunning advances of late 19th and early 20th century physics, logic, and mathematics raised new philosophical questions, requiring new approaches. Carnap took these questions seriously, bringing science to the center of philosophy.

Chapter 7 explores several fascinating, but flawed, logical empiricist positions: (i) its view of itself, articulated by Schlick and Carnap, as the historical turning point in philosophy, in which the logical analysis of language and science would decisively replace metaphysics, (ii) its linguistic theory of the apriori, espoused by Hans Hahn, (iii) Schlick's foundationalist theory of knowledge, (iv) and the unsuccessful struggles of Carl Hempel and Hans Reichenbach, to assimilate truth to confirmation or high probability.

Chapter 8 chronicles the great advances made by Godel, Tarski, Church, and Turing. After presenting the simple idea behind the incompleteness of 1st-order arithmetic, and the arithmetical indefinability of arithmetical truth, I work through Godel's theorem that no omega-consistent extensions of a certain first-order theory of arithmetic are complete. This is followed by the Rosser strengthening that substitutes ordinary consistency for omega-consistency. I then explain why the completeness of 2nd-order arithmetic doesn't undermine the significance of 1 storder incompleteness. The second incompleteness theorem-the unprovability of consistency - is proved, demonstrating that vastness of first-order incompleteness. The undecidability of 1st-order logic is then established, via the Church and the Turing methods. It was during this period that what started with philosophicallyminded mathematicians and mathematically-minded philosophers came to maturity. The project launched by Frege and Russell led not only to new departures in philosophical logic and philosophy of language, but to new deductive disciplinesset theory, model theory, proof theory, and recursive (computable) function theory, providing, among other things, the foundations of the digital age.

Chapter 9 deals with Tarski's truth definition and Carnap's reaction to it After explaining why Tarski wanted a definition, his strategy for giving it, and the details of its execution, I take up, and dispel, a persistent illusion about how his defined notion relates to our ordinary notion of truth. I then try to show how and why his definition was theoretically fruitful, despite not giving us an analysis of truth. I close by dissecting Carnap's flawed Tarskian epiphany, which freed him to treat truth as semantically and philosophically significant, despite wrongly assimilating Tarskitruth to ordinary truth,

Chapter 10 focuses on analyticity, necessity, and apriority. Logical empiricists mistakenly took philosophy to be necessary and apriori, while appealing to analyticity to explain both. This was unfortunate. Some sentences may be analytic in the sense that learning the conventions endowing them with meaning may be sufficient for knowledge of their truth. But necessity and apriority are properties of propositions. No sentence is necessarily true, because it is contingent what conventions govern it. Similarly, it is knowable apriori that no unmarried man is married, because knowing this doesn't require empirical justification. But one can't know that 'No unmarried man is married' is true without having empirical evidence about what the sentence means. Failure to recognize the significance of these 
observations comes from confusing knowing apriori that $S$ with knowing that ' $S$ ' is true simply by understanding ' $\mathrm{S}$ '. In addition to undermining the linguistic theory of the apriori, these considerations suggest that, instead of viewing his creative analyses of scientific concepts as fitting his model of philosophical model of necessary, apriori truths, Carnap might better have viewed them as contingent contributions to empirical theories, including the young science of linguistic semantics.

Chapter 11 is a detailed discussion of the most important attempts of formulate an acceptable version of the empiricist criterion of meaning. Since all such attempts failed, the chapter ends with lessons to be drawn.

Part Three, Is Ethics Possible?, examines the normative and meta-ethical views of leading philosophers of the period. We are accustomed to thinking of ethics in the age of logical empiricism as having been, except for David Ross's intuitionism, replaced by emotivist metaethics, which repudiated normative ethics. Although this familiar picture is largely accurate, it's not entirely so. There was, in addition to Ross's anti-naturalist moral realism, the now all-but-forgotten naturalist moral realism of Schlick. Part Three fills out this historical picture. Chapter 13 explains the rise of emotivism, the arguments against it, and its historical legacy. Chapter 14 discusses H.A. Pritchard's intuitionism and assesses Ross's theory of moral obligation. Chapter 12 lays out the startling conception of ethics as a science in Schlick (1930 [1939]).

Schlick sees that the power of statements of moral obligation to guide action depends on their ability to motivate us. He believes that psychology will inform us that our social impulses, which connect us to others and lead us to value them, are as important to us as our narrowly self-regarding impulses. According to Schlick, these are the source, not only of moral norms we wish to fulfill, but also of much of our happiness. If we didn't have these values, moral claims would, he thought, be empty, just as they would be for a race of relentlessly self-interested rational agents. There is no sense asking "Is what we most fundamentally value really valuable?" In the end, we simply value what we do, for psycho-biological reasons. For Schlick, ethics is (potentially) a science because the truth of ethical statements depends on the truths of psycho-biology. Chapter 12 ends by drawing parallels between Schlick's view and that of one of the most celebrated social scientists of the second half of the 20th century.

At the beginning of chapter 14, I highlight a possible connection between Schlick's conception and Pritchard's interesting, though elusive, views on moral knowledge and motivation, expressed in his fascinating paper Prichard (1912), "Does Morality Rest on a Mistake?" There he asks What leads us to act morally when doing so isn't in our interest? Not, he thought, moral arguments. Rather, after imaginatively thinking about all aspects of a possible act $\mathrm{A}$ in a situation $\mathrm{S}$, we come to see, immediately and non-inferentially, that performing $A$ in $S$ would have a morally relevant feature of a particular kind. This, and this alone, motivates us to act.

Regrettably, Pritchard doesn't succeed in illuminating what this amounts to, or in developing a plausible moral epistemology based on it. However, what he describes may be explainable from Schlick's perspective. We come, in the situation, to 
experience, directly or imaginatively, the conflicting or reinforcing interactions of positive or negative morally relevant features of the contemplated action-e.g., the severity of harm, the type of betrayal, or the depth of expected loyalty. It is by experiencing these things "from the inside" that we come to a decision. The feelings provoked in the process put us in touch with the sources of our moral evaluations, allowing us to see what we had previously missed-namely, how the action touches our deeply felt values. To make judgments in these cases is to recognize motivationally forceful reasons for acting. (See pp. 384-387 of Soames (2018)).

\section{References}

Carnap, R (1928 [1967]). The logical structure of the world and pseudoproblems of philosophy (A. G. Rolf, Trans.). Berkeley: University of California Press. (Originally published as Der logische Aufbau der Welt. Leipzig: Felix Meiner Verlag).

Hahn, H., Carnap, R., \& Neurath, O. (1929). The scientific conception of the world. Pamphlet. (Trans. and Reprinted from The emergence of logical empiricism, vol. 1, by S. Sarkar, Ed., (1966), New York: Garland Publishing).

Pritchard, H. A. (1912). Does morality rest on a mistake? Mind, 21, 21-37.

Schlick, M. (1930 [1939]). Problems of ethics. (R. David, Trans.). New York: Prentice Hall. (Originally published as Fragen der Ethik, Vienna: Springer).

Soames, S. (2018). The analytic tradition in philosophy, (Vol. 2). Princeton and Oxford: Princeton Press. Wittgenstein, L. (1914-1916). Notebooks. 1914-1916 (G. H. von Wright \& G. E. M. Anscombe, Trans.). 2nd edn., G.E.M. Anscombe. Oxford: Blackwell.

Wittgenstein, L. (1922 [1999]). Tractatus logico-philosophicus. (C. K. Ogden, Trans.). London: Routledge and Kegan Paul. (Reprinted From Dover, 1999).

Publisher's Note Springer Nature remains neutral with regard to jurisdictional claims in published maps and institutional affiliations. 